University of Nebraska - Lincoln

DigitalCommons@University of Nebraska - Lincoln

Management Department Faculty Publications

Management Department

$1-2009$

\title{
Leadership: Current Theories, Research, and Future Directions
}

Bruce Avolio

University of Nebraska - Lincoln, bavolio@u.washington.edu

Fred Walumbwa

Arizona State University, fred.walumbwa@asu.edu

Todd J. Weber

University of Nebraska - Lincoln, drawkcab321@gmail.com

Follow this and additional works at: https://digitalcommons.unl.edu/managementfacpub

Part of the Management Sciences and Quantitative Methods Commons

Avolio, Bruce; Walumbwa, Fred; and Weber, Todd J., "Leadership: Current Theories, Research, and Future Directions" (2009). Management Department Faculty Publications. 37.

https://digitalcommons.unl.edu/managementfacpub/37

This Article is brought to you for free and open access by the Management Department at DigitalCommons@University of Nebraska - Lincoln. It has been accepted for inclusion in Management Department Faculty Publications by an authorized administrator of DigitalCommons@University of Nebraska - Lincoln. 


\title{
Leadership: Current Theories, Research, and Future Directions
}

\author{
Bruce J. Avolio, ${ }^{1}$ Fred O. Walumbwa, ${ }^{2}$ and Todd J. Weber ${ }^{3}$ \\ ${ }^{1}$ Department of Management, University of Nebraska-Lincoln, \\ Lincoln, NE 68588-0491; email: bavolio2@unl.edu \\ ${ }^{2}$ Department of Management, The Arizona State University, \\ Glendale, Arizona 85306-4908; email: fred.walumbwa@asu.edu \\ ${ }^{3}$ Department of Management, University of Nebraska-Lincoln, \\ Lincoln, NE 68588-0491; email: tweber2@unl.edu
}

\begin{abstract}
This review examines recent theoretical and empirical developments in the leadership literature, beginning with topics that are currently receiving attention in terms of research, theory, and practice. We begin by examining authentic leadership and its development, followed by work that takes a cognitive science approach. We then examine new-genre leadership theories, complexity leadership, and leadership that is shared, collective, or distributed. We examine the role of relationships through our review of leader member exchange and the emerging work on followership. Finally, we examine work that has been done on substitutes for leadership, servant leadership, spirituality and leadership, cross-cultural leadership, and e-leadership. This structure has the benefit of creating a future focus as well as providing an interesting way to examine the development of the field. Each section ends with an identification of issues to be addressed in the future, in addition to the overall integration of the literature we provide at the end of the article.
\end{abstract}

Keywords: authentic leadership, cognitive leadership, complexity leadership, cross-cultural leadership, new-genre leadership, shared leadership

\section{Contents}

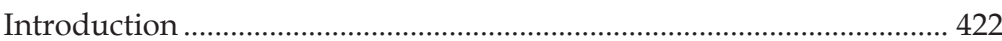

Overview of Authentic Leadership ............................................................423

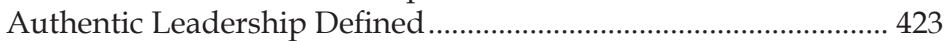

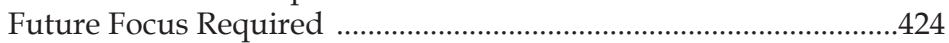

Authentic Leadership Development ..........................................................424

Heritability and Leadership ............................................................. 425

Examining Evidence for Positive Leadership Interventions ........ 425

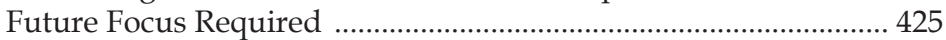

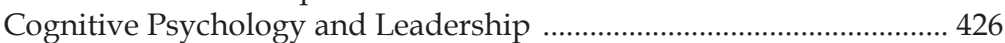

Emerging Cognitive Constructs ......................................................426

Prototypical Abstractions of Leadership .......................................... 427

Future Focus Required ......................................................................428 
New-Genre Leadership .........................................................................428

New-Genre Versus Traditional Leadership .................................... 428

Boundary Conditions for New-Genre Leadership ..........................429

Future Focus Required .................................................................... 429

Complexity Leadership............................................................................... 430

Complexity and Traditional Leadership Theory ............................ 430

Future Focus Required ..................................................................... 431

Shared, Collective, or Distributed Leadership .........................................431

Shared Leadership Defined ................................................................431

Research Evidence ..........................................................................432

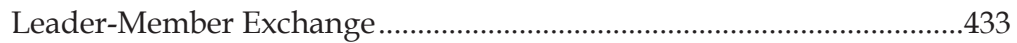

Extensions to LMX ........................................................................ 433

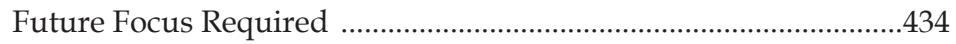

Followership and Leadership ................................................................ 434

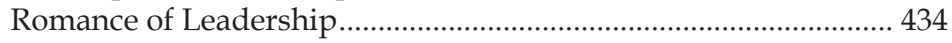

Updates on Follower-Centric Views ..................................................435

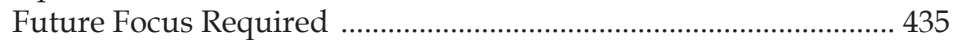

Substitutes for Leadership .................................................................... 436

Future Focus Required ................................................................ 436

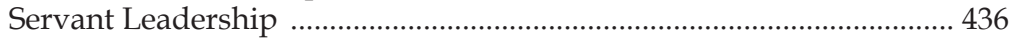

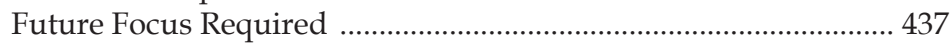

Spirituality and Leadership........................................................................437

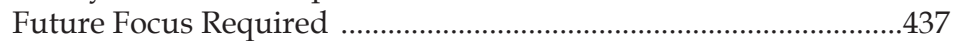

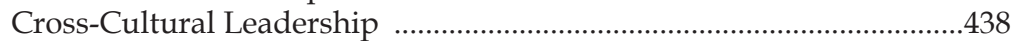

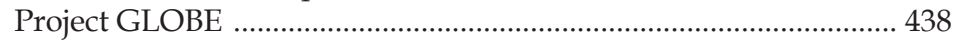

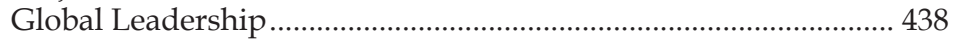

Comparative Leadership .............................................................. 439

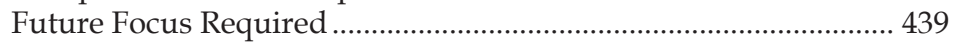

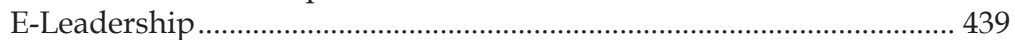

Common Questions with E-Leadership ........................................ 440

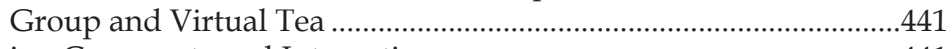

Closing Comments and Integration ...........................................................441

\section{Introduction}

One of our goals for this integrative review is to examine the ways in which the field of leadership is evolving and the consequences of its evolutionary path for the models, methods, and populations examined. For example, at the outset of the field of leadership, the primary focus was on studying an individual leader, who was most likely a male working in some large private-sector organization in the United States. Today, the field of leadership focuses not only on the leader, but also on followers, peers, supervisors, work setting/context, and culture, including a much broader array of individuals representing the entire spectrum of diversity, public, private, and not-for-profit organizations, and increasingly over the past 20 years, samples of populations from nations around the globe. Leadership is no longer simply described as an individual character- 
istic or difference, but rather is depicted in various models as dyadic, shared, relational, strategic, global, and a complex social dynamic (Avolio 2007, Yukl 2006).

We organize our examination of how leadership is evolving by discussing significant areas of inquiry that represent current pillars in leadership research, some understandably taller than others. We highlight the current state of each particular area of inquiry, and discuss what we know, what we don't know, and what remains interesting possibilities to pursue in future research. Given our space limitations, we focus more on the current state of these respective areas in terms of advances in theory, research, and practice, including the criticisms and boundaries of theories, models, and methods wherever appropriate. From this analysis, we offer some recommendations for future directions that the science of leadership could pursue, and we discuss the potential implications for leadership practice.

Looking back over the past 100 years, we cannot imagine a more opportune time for the field of leadership studies. Never before has so much attention been paid to leadership, and the fundamental question we must ask is, what do we know and what should we know about leaders and leadership? We begin addressing these questions not by going back to the earliest work in leadership, but rather by focusing on what is most current in the field. We then examine other areas from which the current work has emerged, rather than examining leadership material covered in recent reviews (Gelfand et al. 2007, Goethals 2005) or providing a comprehensive historical review of the field that is better left to the Handbook of Leadership (Bass \& Bass 2008; see also Yukl \& Van Fleet 1992).

\section{Overview of Authentic Leadership}

One of the emerging pillars of interest in the field of leadership has been called authentic leadership development. As discussed in a special issue [edited by Avolio \& Gardner (2005)] of the Leadership Quarterly on this topic and in an earlier theoret- ical piece by Luthans \& Avolio (2003), the advent of work on authentic leadership development came as a result of writings on transformational leadership, in which authors such as Bass \& Steidlmeier (1999) suggest that there are pseudo versus authentic transformational leaders.

Luthans \& Avolio (2003) also introduced the concept of authentic leadership development into the literature with the goal of integrating work on (Luthans 2002) positive organizational behavior with the life-span leadership development work of Avolio (1999). Their main purpose was to examine what constituted genuine leadership development including what worked and didn't work to develop leaders and leadership, as well as to bring to the foreground some of the recent work in positive psychology as a foundation for examining how one might accelerate the development. Luthans and Avolio reasoned that using some of the theoretical work in positive psychology such as Fredrickson's (2001) broaden-and-build theory, they could offer a more positive way for conceptualizing leadership development. According to Fredrickson, those individuals who have more positive psychological resources are expected to grow more effectively or to broaden themselves and build out additional personal resources to perform. Luthans and Avolio report that to a large extent, the prior leadership development work was based on a deficit-reduction model strategy, where one discovered what was wrong with a leader and then worked to correct deficits in terms of focusing on the leader's development (also see Avolio \& Luthans 2006).

\section{Authentic Leadership Defined}

First and foremost, the concept of authenticity has been around for a long time, as reflected in many philosophical discussions of what constitutes authenticity (Harter et al. 2002). George (2003) popularized authentic leadership in the general practice community when he published his book on the topic, as did Luthans \& Avolio (2003) for the academic community. Luthans \& Avolio (2003, p. 243) defined authentic lead-
Authentic leadership: a pattern of transparent and ethical leader behavior that encourages openness in sharing information needed to make decisions while accepting followers' inputs

Transformational leadership: leader behaviors that transform and inspire followers to perform beyond expectations while transcending selfinterest for the good of the organization

Positive organizational behavior: literature that is focusing on positive constructs such as hope, resiliency, efficacy, optimism, happiness, and well-being as they apply to organizations

Broaden-and-build theory: suggests positive emotions expand cognition and behavioral tendencies, and encourage novel, varied, and exploratory thoughts and actions 
Ethical leadership: the demonstration of normatively appropriate conduct through personal actions and interpersonal relationships, and the promotion of such conduct to followers

Nomological network: a representation of a construct, its observable manifestation, and the relationship between the two ership as "a process that draws from both positive psychological capacities and a highly developed organizational context, which results in both greater self-awareness and self-regulated positive behaviors on the part of leaders and associates, fostering positive self-development." This definition and subsequent work on authentic leadership was defined at the outset as multilevel in that it included the leader, follower, and context very specifically in the way it was conceptualized and measured. This addressed a typical criticism in the leadership literature summarized by Yammarino et al. (2005, p. 10) who concluded, "relatively few studies in any of the areas of leadership research have addressed levels-of-analysis issues appropriately in theory, measurement, data analysis, and inference drawing."

At the same time, several scholars (e.g., Cooper et al. 2005, Sparrowe 2005) expressed concerns with Luthans \& Avolio's initial definition of authentic leadership. The initial conceptual differences notwithstanding, there appears to be general agreement in the literature on four factors that cover the components of authentic leadership: balanced processing, internalized moral perspective, relational transparency, and self-awareness. Balanced processing refers to objectively analyzing relevant data before making a decision. Internalized moral perspective refers to being guided by internal moral standards, which are used to self-regulate one's behavior. Relational transparency refers to presenting one's authentic self through openly sharing information and feelings as appropriate for situations (i.e., avoiding inappropriate displays of emotions). Selfawareness refers to the demonstrated understanding of one's strengths, weaknesses, and the way one makes sense of the world. These four constructs were further operationally defined by Walumbwa and colleagues (2008). Walumbwa et al. (2008) provided initial evidence using a multisample strategy involving U.S. and non-U.S. participants to determine the construct validity of a new set of authentic leadership scales. Specifically, they showed the four components described above represented unique scales that were reliable. These four scales loaded on a higher-order factor labeled authentic leadership that was discriminantly valid from measures of transformational leadership (e.g., Avolio 1999) and ethical leadership (e.g., Brown et al. 2005) and was a significant and positive predictor of organizational citizenship behavior, organizational commitment, and satisfaction with supervisor and performance.

\section{Future Focus Required}

Work on defining and measuring authentic leadership is in the very early stages of development. Future research will need to offer additional evidence for the construct validity of this measure or other measures, and it will also need to demonstrate how authentic leadership relates to other constructs within its nomological network. This would include constructs such as moral perspective, self-concept clarity, well-being, spirituality, and judgment. Moreover, there is a need to examine how authentic leadership is viewed across situations and cultures and whether it is a universally prescribed positive root construct-meaning it represents the base of good leadership regardless of form, e.g., participative, directive, or inspiring. In the next section, we turn our attention to the second major focus on authentic leadership, which incorporates the term development.

\section{Authentic Leadership Development}

Up until very recently, one would be hard-pressed to find in the leadership literature a general model of leadership development (Luthans \& Avolio 2003). Even more difficult to find is evidence-based leadership development. Specifically, what evidence is there to support whether leaders or leadership can be developed using one or more specific theories of leadership? This question led to a concerted effort to explore what was known about whether leaders are born or made, as well as the efficacy of leadership interventions. 


\section{Heritability and Leadership}

One avenue of research that has explored whether leaders are born versus made has involved studying identical and fraternal twins. Preliminary evidence using a behavioral genetics approach has shown that approximately $30 \%$ of the variation in leadership style and emergence was accounted for by heritability; the remaining variation was attributed to differences in environmental factors such as individuals having different role models and early opportunities for leadership development (Arvey et al. 2007). Because identical twins have $100 \%$ of the same genetic makeup and fraternal twins share about $50 \%$, this behavioral genetics research was able to control for heritability to examine how many leadership roles the twins emerged into over their respective careers. In this and subsequent research for both men and women across cultures, similar results were obtained. The authors conducting this research conclude that the "life context" one grows up in and later works in is much more important than heritability in predicting leadership emergence across one's career.

\section{Examining Evidence for Positive Leadership Interventions}

Lord \& Hall (1992, p. 153) noted, "too much research in the past has attempted to probe the complex issues of leadership using simple bivariate correlations." It seems fair to say that although most models of leadership have causal predictions, a relatively small percentage of the accumulated literature has actually tested these predictions using controlled leadership interventions, especially in field research settings (Yukl 2006).

To determine whether experimental interventions actually impacted leadership development and/or performance, a qualitative and quantitative review of the leadership intervention (i.e., studies where a researcher overtly manipulated leadership to examine its impact on some specific intermediate process variables or outcomes) literature was undertaken (see Avolio \& Lu- thans 2006, Avolio et al. 2009, Reichard \& Avolio 2005). The focus of this meta-analytic review was unique in that up to that point, more than 30 meta-analyses had been published on leadership research, none of which had focused on leadership interventions and more than one model of leadership. For each study, the leadership intervention examined was categorized into six types: training, actor/role-play, scenario/ vignette, assignments, expectations, others. Reichard \& Avolio (2005) reported that regardless of the theory being investigated, results showed that leadership interventions had a positive impact on work outcomes (e.g., ratings of leader performance), even when the duration of those interventions was less than one day. In terms of utility, participants in the broadly defined leadership treatment condition had on average a $66 \%$ chance of positive outcomes versus only a $34 \%$ chance of success for the comparison group.

\section{Future Focus Required}

Relatively little work has been done over the past 100 years to substantiate whether leadership can actually be developed. Indeed, based on the meta-analysis findings reviewed above, only 201 studies were identified that fit the intervention definition. Of those 201 studies, only about one third focused on developing leadership as opposed to manipulating it for impact through role plays or scripts to test a particular proposition in one of the various models.

One of the emerging areas of interest in leadership research, which we have dedicated more attention to in its own section, concerns the linkages between cognitive science and how leaders perceive, decide, behave, and take action (Lord \& Brown 2004). For example, to develop leadership, it is imperative that we examine how a leader's self-concept and/or identity is formed, changed, and influences behavior (Swann et al. 2007). This raises a key question regarding what constitutes leaders' working selfconcept and/or identity with respect to how they go about influencing others (Swann et 
Cognitive leadership: a broad range of approaches to leadership emphasizing how leaders and followers think and process information al. 2007). For example, does an authentic leader have a different working self-concept than someone who is described by followers as transformational or transactional, and how do these differences develop in the leader over time?

We know from previous literature that although a leader's working self-concept is constructed in the current moment, it is also based on more stable self-concepts and identities stored in the individual's longterm memory. Avolio \& Chan (2008) indicate there are certain trigger events that activate the leader's working self-concept. These trigger events induce self-focused attention, self-assessment, and activate a leader's working self-concept. These trigger moments can occur naturally as the leader interacts with others during leadership episodes or they can be induced through formal training exercises and self-reflection (Roberts et al. 2005).

Another very promising area of research that has not received sufficient attention in the leadership literature focuses on understanding what constitutes an individual's level of developmental readiness or one's capacity or motivational orientation to develop to one's full potential. Prior authors have defined developmental readiness as being made up of components such as one's goal orientation (Dweck 1986) and motivation to develop leadership (Maurer \& Lippstreu 2005). In this literature, the authors argue that leaders who are more motivated to learn at the outset and who have higher motivation to lead will more likely embrace trigger events that stimulate their thinking about their own development as an opportunity to improve their leadership effectiveness.

In sum, a great deal of energy and interest is emerging in the leadership development literature that suggests there will be a lot more activity in trying to discover what impacts genuine leadership development at multiple levels of analysis, from cognitive through to organizational climates. This literature will no doubt link to the life-span development and cognitive psychology literatures to fuel further work in this area.

\section{Cognitive Psychology and Leadership}

The cognitive science leadership literature is an area of research and theory containing a wide range of approaches that are united by their focus on explaining the way leaders and followers think and process information. This literature includes a broad range of topics such as self-concept theory, meta-cognitions, and implicit leadership theory (e.g., Lord \& Emrich 2000), which are addressed in more detail below.

One of the more recent developments in the literature has been an attempt to develop models of leadership cognition. Lord \& Hall (2005) developed a model of leadership development that emphasized the leader's cognitive attributes or abilities. A second model was developed by Mumford et al. (2003) and examined the way shared thinking contributed to leader creativity. These two approaches illustrate a fundamental way in which views of leadership cognitions vary, with the former focusing on activities with the individual leader and the latter focusing on interactions that occur between individuals (Mumford et al. 2007). We examine several of the key emerging constructs within this literature, beginning with the self-concept.

\section{Emerging Cognitive Constructs}

Recent literature on what constitutes the self-concept has distinguished between the structure of the self-concept and its contents (Altrocchi 1999). The content refers to the evaluations one makes of oneself as well as self-beliefs. The structure refers to ways in which the self-concept content is organized for processing. In a study on the structure of the self-concept, Campbell et al. (2003) examined the competing arguments that one benefits from having either unity in selfconcept or pluralism. Although the literature tends to treat the two as opposite ends of a continuum, their study showed they are not necessarily related to each other. This study further showed that two measures of pluralism (self-complexity and self-concept compartmentalization) were not related to 
each other and that multiple measures of self-concept unity, such as self-concept differentiation, self-concept clarity, and selfdiscrepancies, were moderately related to each other and that each had implications for leader development.

Lord \& Brown (2001) presented a model examining two specific ways that leaders can influence the way followers choose to behave in terms of the motivations they use to regulate actions/behaviors. The first way relates to values (e.g., achievement) and emphasizes making specific values (or patterns of values) salient for the follower to motivate him or her to action. The second relates to the followers' self-concept, whereby the leader activates a specific identity to which followers can relate, creating a collective identity that the follower ultimately embraces as his or her own. Both values and self-concept are viewed as mediating the linkage between the leader's actions and the behavior of the follower.

Because there are a range of peripheral and core identities that could be salient to an individual at any one point in time, the question of which identities are activated at any time is relevant to research on leadership and its impact on followers. The idea of a working self-concept refers to the identity (or combination of identities) that is salient in the moment, and it consists of three types of components: self-views, current goals, and possible selves (Lord \& Brown 2004). The self-view relates to the current working model or view of oneself, whereas the possible selves may represent the ideal model an individual may be striving for and something that could be leveraged by the leader to motivate and develop followers into better followers or leaders themselves. Overall, the working self-concept has the potential to provide insight into the challenging issue of how salient one's identity is and how leadership can enhance its salience, though its use within the leadership literature has been somewhat limited so far.

One of the essential building blocks in the cognitive leadership literature is the idea of a schema, which is a broad organiz- ing framework that helps one understand and make sense of a given context or experience. One notable example of the use of schemas with respect to leadership research is the work of Wofford et al. (1998), who proposed a cognitive model to explain the way transformational and transactional leaders view work with followers. In their field study, Wofford et al. examined schematic processes (e.g., vision, follower, self) and scripts (behaviors associated with a schema), arguing that transformational and transactional leadership use different schemas to interpret events, which then results in the choice of different leadership behaviors/actions in response to those events. Support was found for transformational leader cognitions being related to the leaders' choice of acting transformationally. Mixed support was found for the relationships between transactional leader schemas and behaviors and actions chosen.

\section{Prototypical Abstractions of Leadership}

The leadership research on social identity formation has also focused heavily on what constitutes prototypicality, which has shown that followers may be more drawn to leaders who are exemplars of groups they belong to or want to join. Early research conceptualized prototypes as being relatively static and applicable in many situations. Recent work has contested that view, arguing that prototypes are dynamic and can be applied and adapted based on the existing constraints or challenges being confronted by leaders (Lord et al. 2001).

Subsequent research has also focused on the relationship between implicit leadership theories and several relevant performance outcomes (Epitropaki \& Martin 2005). We note that for more than 25 years, a great deal of the work on cognitive psychology and leadership focused on how implicit theories and prototypes affected the perceptions of leaders and followers, generally examining how it disadvantaged or biased them in views of others. More recent trends in this literature coincide nicely with
Transactional leadership: leadership largely based on the exchange of rewards contingent on performance 
emphasis now being placed on authentic leadership development. Specifically, research is now attempting to link how leaders think about events, choose to behave, and/or develop.

\section{Future Focus Required}

Cognitive approaches to investigating leadership draw heavily on several literatures described above. This broad stream of research has potential for enhancing existing theories of leadership in terms of helping to explain how leaders and followers attend to, process, and make decisions and develop. Additional work linking self-concept and meta-cognitive theories to research on leadership will no doubt contribute to our understanding of how leaders and followers actually develop. For example, if a leader has low self-concept clarity, to what extent can we expect that same leader to be self-aware? What are the implications for enhancing a leader's self-concept clarity or working self-concept about what constitutes the roles of effective leadership in developing that leader's self-awareness and performance?

\section{New-Genre Leadership}

New-genre leadership: leadership emphasizing charismatic leader behavior, visionary, inspiring, ideological and moral values, as well as transformational leadership such as individualized attention, and intellectual stimulation

\section{New-Genre Versus Traditional Leadership}

Bryman (1992) commented, "There was considerable disillusionment with leadership theory and research in the early 1980s. Part of the disillusionment was attributed to the fact that most models of leadership and measures accounted for a relatively small percentage of variance in performance outcomes such as productivity and effectiveness. Out of this pessimism emerged a number of alternative approaches, which shared some common features..., collectively referred to as the new leadership" (Bryman 1992, p. 21). Unlike the traditional leadership models, which described leader behavior in terms of leader-follower exchange relationships, setting goals, providing direction and support, and reinforcement behaviors, or what Bass (1985) referred to as being based on "economic cost-benefit assumptions" (p. 5), the new leadership models emphasized symbolic leader behavior; visionary, inspirational messages; emotional feelings; ideological and moral values; individualized attention; and intellectual stimulation. Emerging from these early works, charismatic and transformational leadership theories have turned out to be the most frequently researched theories over the past 20 years (Avolio 2005, Lowe \& Gardner 2000).

The theory of charismatic/transformational leadership suggests that such leaders raise followers' aspirations and activate their higher-order values (e.g., altruism) such that followers identify with the leader and his or her mission/vision, feel better about their work, and then work to perform beyond simple transactions and base expectations (e.g., Avolio 1999, Bass 1985, Conger \& Kanungo 1998). Accumulated research (see Avolio et al. 2004a for a summary of this literature), including a series of meta-analytic studies (e.g., Judge \& Piccolo 2004), has found that charismatic/transformational leadership was positively associated with leadership effectiveness and a number of important organizational outcomes across many different types of organizations, situations, levels of analyses, and cultures such as productivity and turnover. 
Over the past decade, a lot of research effort has been invested in understanding the processes through which charismatic/ transformational leaders positively influence followers' attitudes, behaviors, and performance. For example, a number of studies have examined different processes through which transformational leadership effects are ultimately realized in terms of performance outcomes. These processes include followers' formation of commitment; satisfaction; identification; perceived fairness (e.g., Liao \& Chuang 2007, Walumbwa et al. 2008); job characteristics such as variety, identity, significance, autonomy and feedback (e.g., Piccolo \& Colquitt 2006); trust in the leader (e.g., Wang et al. 2005); and how followers come to feel about themselves and their group in terms of efficacy, potency, and cohesion (e.g., Bass et al. 2003, Bono \& Judge 2003, Schaubroeck et al. 2007).

\section{Boundary Conditions for New-Genre Leadership}

After establishing the positive links between transformational leadership and the intervening variables and performance outcomes, more recent research has examined the boundary conditions in which transformational leadership is more (or less) effective in predicting follower attitudes and behaviors. For example, several studies have focused on identifying and understanding contextual variables (e.g., idiocentrism) that mediate or moderate the relationship of charismatic/transformational leadership with followers' level of motivation and performance at the individual, team or group, and organizational levels (e.g., De Cremer \& van Knippenberg 2004, Keller 2006, Walumbwa et al. 2007). Additional research has focused on examining the moderating effects of follower dispositions such as efficacy (Dvir \& Shamir 2003, Zhu et al. 2008), physical and structural distance (e.g., Avolio et al. 2004b), perceived environmental uncertainty (e.g., Agle et al. 2006), social networks (e.g., Bono \& Anderson 2005), technology to support group decision-mak- ing (e.g., Sosik et al. 1997), and cultural orientations such as collectivism (e.g., Walumbwa \& Lawler 2003).

\section{Future Focus Required}

Although significant progress has been made in studying charismatic/transformational leadership, a number of areas still deserve further attention. First, despite the important and positive contributions made by charismatic or transformational leadership in practice, questions remain as to what determines or predicts charismatic or transformational leadership, or why some leaders engage in charismatic or transformational leadership behavior and others do not. Limited research has examined leaders' biographies or the role of followers (Howell \& Shamir 2005) as predictor variables.

Second, despite significant progress in understanding how and when charismatic and transformational leadership behaviors are more effective, further research is needed that explores the process and boundary conditions for charismatic and transformational leadership with beneficial work behaviors. For example, although scholars who have investigated charismatic and transformational leadership have discussed motivational constructs as central components in their frameworks, generally speaking, few have paid any attention to the underlying psychological processes, mechanisms, and conditions through which charismatic and transformational leaders motivate followers to higher levels of motivation and performance (Kark \& Van Dijk 2007).

Yukl (1999) has called for a more concerted effort to understand both the moderating and mediating mechanisms that link charismatic/transformational leadership to follower outcomes. To date, only a few preliminary studies have simultaneously examined mediated moderation or moderated mediation (e.g., De Cremer \& van Knippenberg 2004, Walumbwa et al. 2008).

Third, other areas that deserve research attention include examining how to link
Mediated moderation: a moderating relationship that is mediated by another variable

Moderated mediation: a mediating relationship that is moderated by another variable 
charismatic/transformational leadership to the emerging literature on emotions and leadership. Although all of these newer theories emphasize the emotional attachment of followers to the leader, there has been a dearth of conceptual and empirical research on examining the relationships between these new leadership theories and followers' affective states (Bono \& Ilies 2006).

Fourth, research on charismatic and transformational leadership at the organizational or strategic level has generally lagged behind all other areas of leadership research except perhaps the focus on leadership development (Waldman \& Yammarino 1999), and the results thus far have been mixed (Agle et al. 2006). For example, Waldman and colleagues (Tosi et al. 2004, Waldman et al. 2001) found that the charisma of the chief executive officer (CEO) was not related to subsequent organizational performance as measured by net profit margin and shareholder return or return on assets, respectively. On the other hand, Agle et al. (2006) and Waldman et al. (2004) reported that CEO charisma was associated with subsequent organizational performance. Clearly, more research is needed that focuses on potential mediating and moderating variables such as external stakeholders while examining the relationship between CEO charismatic or transformational leadership and firm performance.

Finally, although cross-cultural research pertaining to charismatic/transformational leadership generally supports the relationships reported for the United States and other Western cultures, it is important to note that these studies largely involve survey-based designs. We recommend that researchers incorporate a number of alternative research designs, including but not limited to experimental designs, longitudinal designs, and qualitative designs, as well as the use of multiple sources and mixed methods studies.

CLT: complexity leadership theory traditional hierarchical structures of organizations. To the degree that organizations are hierarchical, so too are leadership models (Uhl-Bien et al. 2007). Yet, there has been a growing sense of tension in the leadership literature that models of leadership that were designed for the past century may not fully capture the leadership dynamic of organizations operating in today's knowledgedriven economy (Lichtenstein et al. 2007). Applying the concepts of complexity theory to the study of leadership has resulted in what has been referred to as complexity leadership (Uhl-Bien \& Marion 2008). Based on this framework, leadership is viewed as an interactive system of dynamic, unpredictable agents that interact with each other in complex feedback networks, which can then produce adaptive outcomes such as knowledge dissemination, learning, innovation, and further adaptation to change (UhlBien et al. 2007). According to complex systems leadership theory, "leadership can be enacted through any interaction in an organization... leadership is an emergent phenomenon within complex systems" (Hazy et al. 2007, p. 2).

In line with leadership fitting the needs of the situation or challenges in which it operates, complexity leadership posits that to achieve optimal performance, organizations cannot be designed with simple, rationalized structures that underestimate the complexity of the context in which the organization must function and adapt (Uhl-Bien et al. 2007). Simply viewing the leader and follower in a simple exchange process won't fly in terms of explaining the full dynamics of leadership.

\section{Complexity and Traditional Leadership Theory}

In traditional leadership theory, the unit of analysis is oftentimes the leader, the leader and follower, the leader and group, and so forth. The fundamental unit of analysis in complexity leadership is referred to as a complex adaptive system, or CAS (UhlBien et al. 2007). The CAS has its roots in the physical sciences and is composed of interdependent agents that can operate simul-
Many previous models of leadership have been designed to accommodate more 
taneously on the basis of certain rules and localized knowledge that governs the CAS, while also being able to adapt and emerge based on feedback from the system (Plowman \& Duchon 2008). Complexity leadership theory (CLT; Uhl-Bien et al. 2007) has been developed as an overarching explanation of how CAS operates within a bureaucratic organization, and it identifies three leadership roles to explore: adaptive (e.g., engaging others in brainstorming to overcome a challenge), administrative (e.g., formal planning according to doctrine), and enabling (e.g., minimizing the constraints of an organizational bureaucracy to enhance follower potential).

\section{Future Focus Required}

One of the core propositions of complexity leadership theory is that "much of leadership thinking has failed to recognize that leadership is not merely the influential act of an individual or individuals but rather is embedded in a complex interplay of numerous interacting forces" (Uhl-Bien et al. 2007 , p. 302). How should one then study this form of leadership? Dooley \& Lichtenstein (2008) describe several methods for studying complex leadership interactions, including by focusing on (a) micro, daily interactions using real-time observation, (b) meso interactions (days and weeks) using social network analysis, where one examines a set of agents and how they are linked over time, and (c) macro interactions (weeks, months, and longer) through event history analysis. Finally, agent-based modeling simulations (i.e., computer simulations based on a set of explicit assumptions about how agents are supposed to operate) are also being used as a means to study complexity leadership.

In sum, the complexity leadership field clearly lacks substantive research. We suspect this is a result of the difficulties in assessing this type of emergent construct within a dynamically changing context. However, substantive research is needed if this area of leadership research is to advance beyond conceptual discussions.

\section{Shared, Collective, or Distributed Leadership}

Similar to our discussion above about complexity leadership, we see more evidence for shared or collective leadership in organizations as hierarchical levels are deleted and team-based structures are inserted. In describing shared and team leadership, it is important to point out that these forms of leadership are typically viewed as different streams of research. For example, team leadership research has typically focused on the role of an individual leading the team. In contrast, those authors examining shared leadership generally view it as a process versus a person engaging multiple members of the team. In this section, we refer to the terms "shared leadership," "distributed leadership," and "collective leadership" interchangeably, paralleling their usage in the leadership literature.

\section{Shared Leadership Defined}

According to Day et al. (2004), team and shared leadership capacity is an emergent state-something dynamic that develops throughout a team's lifespan and that varies based on the inputs, processes, and outcomes of the team. It produces patterns of reciprocal influence, which reinforce and develop further relationships between team members (Carson et al. 2007). The most widely cited definition of shared leadership is that of Pearce \& Conger (2003): "a dynamic, interactive influence process among individuals in groups for which the objective is to lead one another to the achievement of group or organizational goals or both. This influence process often involves peer, or lateral, influence and at other times involves upward or downward hierarchical influence" (p. 1). The term shared leadership overlaps with relational and complexity leadership, and differs from more traditional, hierarchical, or vertical models of leadership (Pearce \& Sims 2002).

Highly shared leadership is broadly distributed within a group or a team of individuals rather than localized in any one indi-
Shared leadership: an emergent state where team members collectively lead each other 
vidual who serves in the role of supervisor (Pearce \& Conger 2003). More specifically, shared leadership is defined as a team-level outcome (Day et al. 2004) or as a "simultaneous, ongoing, mutual influence process within a team that is characterized by 'serial emergence' of official as well as unofficial leaders" (Pearce 2004, p. 48). Similar to what we've described with respect to complexity leadership, when shared leadership can be "viewed as a property of the whole system, as opposed to solely the property of individuals, effectiveness in leadership becomes more a product of those connections or relationships among the parts than the result of any one part of that system (such as the leader)" (O'Connor \& Quinn 2004, p. 423).

\section{Research Evidence}

Although a number of authors [beginning with Mary Parker Follett (1924)] have discussed the idea of shared leadership, it has only gained attention in the academic leadership literature recently, and relatively few studies have tried to measure shared leadership. One exception is the work by Avolio \& Bass (1995). In their study, instead of raters evaluating the individual leader, the target of ratings was the team itself. Avolio \& Bass (1995) report that the team-level measures of transformational and transactional leadership positively predicted performance similar to the individual-level measures in previous research.

\section{Future Focus Required}

One of the criticisms of research on shared leadership involves the lack of agreement on its definition (Carson et al. 2007). For example, should there be a generic definition of shared leadership that is qualified by such terms as transactional or transformational shared leadership?

Other potential areas that have yet to be explored involve certain boundary conditions, mediators, and moderators that have been recommended as a focus for future research. For example, Pearce \& Conger (2003) noted that future research was needed to examine potential moderators such as the dis- tribution of cultural values, task interdependence, task competence, task complexity, and the team life cycle. Carson et al. (2007) proposed that greater attention be paid to levels of task competence in the team, complexity of tasks, and task interdependence in terms of examining how teams function when using shared leadership. These authors have also recommended that future research focus on the team's life cycle.

Another area that has not received much research attention involves the environment in which teams function. For example, Carson et al. (2007) proposed that future research examine the type of team environment that enables shared leadership, suggesting that the environment consists of three "highly interrelated and mutually reinforcing" dimensions: shared purpose, social support, and voice. These authors described several organizational climate factors that could potentially support more shared leadership in teams, including (a) shared purpose, which "exists when team members have similar understandings of their team's primary objectives and take steps to ensure a focus on collective goals"; (b) social support, described as "team members' efforts to provide emotional and psychological strength to one another. This helps to create an environment where team members feel their input is valued and appreciated"; and (c) voice, which is "the degree to which a team's members have input into how the team carries out its purpose" (p. 1222).

Future research also needs to examine how external team leaders affect the team's ability and motivation to be self-directed and share in leadership (Carson et al. 2007). Hackman \& Wageman (2005) suggest that an external leader to the team can "help team members make coordinated and taskappropriate use of their collective resources in accomplishing the team's task" (p. 269).

In a nutshell, the time for examining shared leadership may be upon us to the extent that organizations are moving into a knowledge driven era where firms are distributed across cultures. This suggests that individual-based "heroic" models of leadership may not be sustainable in and of themselves (Pearce 2004). 


\section{Leader-Member Exchange}

Unlike shared leadership, which has focused on groups, leader-member exchange (LMX) theory has focused on the relationship between the leader and follower (Cogliser \& Schriesheim 2000). The central principle in LMX theory is that leaders develop different exchange relationships with their followers, whereby the quality of the relationship alters the impact on important leader and member outcomes (Gerstner \& Day 1997). Thus, leadership occurs when leaders and followers are able to develop effective relationships that result in mutual and incremental influence (Uhl-Bien 2006).

This literature has evolved from focusing exclusively on the consequences of the LMX relationship to focusing on both antecedents and consequences. For example, Tekleab \& Taylor (2003) assessed leader and follower levels of agreement on their mutual obligations and their psychological contract with each other. In a recent metaanalysis reported by Ilies et al. (2007), the authors reported that a higher-quality LMX relationship not only predicted higher levels of performance, but also organizational citizenship behaviors. Some additional areas of focus in terms of high- versus low-quality LMX relationships have been the context in which those relationships have developed. Kacmar et al. (2007) examined the conditions under which leaders and followers in low-quality exchanges exerted more effort in examining how the situation interacted with the impact of supervisors. Using control theory, the authors tried to explain how perceptions of supervisor competence, centralization, and organizational politics influenced their willingness to exert effort on the job beyond what would be typically expected in a less-than-effective exchange relationship.

Additional research on the nature of the relationship and how it is formed has focused on the use of impression management tactics and its impact on the quality of the LMX relationship. Colella \& Varma (2001) investigated how a follower's perceived disability and use of ingratiation re- lated to LMX quality. By using ingratiation tactics, the individuals with disabilities were able to increase the quality of the relationship between the leader and follower. Similar results were reported by Sparrowe et al. (2006), who showed that downwardinfluence tactics used by the leader affected the quality of the LMX relationship.

\section{Extensions to LMX}

The original work produced by Graen \& Uhl-Bien (1995) on the role-making and role-taking processes has been extended by Uhl-Bien and colleagues (2000) to examine how leader-follower dyads transform from individual interest to shared interest based on the development of trust, respect, and obligations to each other. Similar work along these lines has examined the effects of goal congruence on the quality of the LMX relationship. This work suggests that to the extent that goals are similar or mutually reinforcing, one would expect to produce a higher-quality LMX relationship.

Additional LMX research on individual differences has examined the impact of gender on the quality of the LMX relationship, although these findings have been mixed. For instance, Adebayo \& Udegbe (2004) reported that followers in opposite-sex dyads perceived a better LMX quality in comparison with those from same-sex dyads.

Recent research has moved beyond examining LMX in terms of antecedents and consequences and has examined the quality of the leader and follower relationship as a moderator and/or mediator of performance. For example, Sparrowe et al. (2006) reported that the quality of the relationship moderated the relationship between downward-influence tactics and helping behaviors. Martin et al. (2005) reported that LMX either fully or partially mediated the relationship between locus of control and several work-related outcomes such as job satisfaction, work-related well-being, and organizational commitment.

In an extension of the linkages between social network theory and LMX, Graen (2006) put forth a recent transformation
LMX: leader-member exchange 
of LMX theory that he refers to as the new LMX-MMX theory of sharing network leadership. Accordingly, both Uhl-Bien (2006) and Graen (2006), building on earlier LMX research, now view organizations as systems of interdependent dyadic relationships, or dyadic subassemblies, and advocate the importance of both formal and informal influences on individual, team, and network flows of behavior.

\section{Future Focus Required}

Over the years, LMX theory and research have been targets of criticism. One pervasive criticism of this literature revolves around measurement. For example, many different measures of LMX have been developed and used since the theory was first proposed (Yukl 2006). Schriesheim et al. (1999, p. 100) argued, "LMX scales seem to have been developed on ad hoc, evolutionary basis, without the presentation of any clear logic or theory justifying the changes which were made." LMX research has also been criticized for failing to conceptualize the social context in which leaders and followers are embedded. With a few exceptions, "the majority of research is, quite explicitly, located at the dyadic level, with very little theorizing or empirical work examining LMX work at the group level" (Hogg et al. 2004, p. 22). In other words, theory and research on LMX have focused on the leader-follower relationship without acknowledging that each dyadic relationship occurs within a system of other relationships (Cogliser \& Schriesheim 2000, Yukl 2006). LMX theory and research also tend to assume that people simply evaluate their own LMX relationship in an absolute sense. According to Hogg et al. (2004), this is an oversimplification of how people judge relationships. The authors argue that it is much more likely that followers evaluate the quality of their LMX relationship not only in the absolute sense (i.e., low versus high), but also with reference to their perception of others' LMX relationships. Another criticism of the LMX literature is that most of it is based on correlation designs. This was a central criticism made by Cogliser \& Schriesheim (2000) regarding the lack of causal results reported in the extensive stream of research associated with LMX research.

LMX research has also been criticized for not including more objective measures of performance (Erdogan \& Liden 2002). Frequently, research in this area has collected performance outcomes that were generated by the leader or supervisor. It is now time to extend this research by collecting independent outcome measures that logically would be influenced by the quality of LMX relationship.

Another promising area for future research is to extend work on LMX theory across cultures. Specifically, what are the implications of national culture for the formation and development of an LMX quality relationship, and in turn how would that link to key organizational outcomes? Preliminary research addressing this question across cultures has produced some interesting results. For example, Chen et al. (2006) reported that regardless of whether the manager was American or Chinese, the quality of the LMX relationship was related to cooperative goal setting or interdependence.

\section{Followership and Leadership}

Perhaps one of the most interesting omissions in theory and research on leadership is the absence of discussions of followership and its impact on leadership. Leadership researchers treat follower attributes as outcomes of the leadership process as opposed to inputs, even though there have been a number of calls over the years to examine the role that followers play in the leadership process (e.g., Shamir 2007).

\section{Romance of Leadership}

Our examination of follower-centric views begins with a focus on what the leadership literature describes as the romance of leadership. Meindl et al. (1985) proposed a social constructionist theory to describe the relationship between leadership and fol- 
lowership. They argued that leadership is significantly affected by the way followers construct their understanding of the leader in terms of their interpretation of his or her personality, behaviors, and effectiveness.

Accumulated research on the romance of leadership has produced mixed findings. Schyns et al. (2007) conducted a meta-analysis to determine whether they could tease out the effects controlling for such things as measurement error and sampling bias while focusing on whether followers had a tendency to romanticize their perceptions of transformational/charismatic leadership. Their results revealed a modest relationship between the romance of leadership and perceptions of transformational/charismatic leadership, accounting for approximately $5 \%$ of the variance in leadership ratings. In another study, Kulich et al. (2007) examined the relevance of the romance of leadership theory through an experiment that compared how the performance of a male and a female leader was viewed by allowing participants to choose how much of a bonus to allocate to the leader. Their results showed that the male CEO's bonus differed substantially depending on the company's performance, whereas no differences were reported for the female CEO.

Bligh et al. (2007) found that followers' negative views of their work environment were overly attributed to their leaders' in that they viewed the leader as more responsible for these negative outcomes and situations than was warranted. Along the same lines, Weber et al. (2001) reported that group success and failure were overly attributed to the leader. However, these authors also reported that attributions of failure to the leader may have had more significant negative repercussions, with the failing team consistently voting to replace their leaders when the situation was more of the cause for the team's failure.

\section{Updates on Follower-Centric Views}

Howell \& Shamir (2005) put forth some important theoretical propositions regarding how follower traits and characteris- tics might influence leader and follower relationships (also see Dvir \& Shamir 2003). Specifically, they identified followers' selfconcept clarity and collective identity as important factors in determining how followers form charismatic relationships with their leader. Howell \& Shamir (2005) then suggested that followers, who have a personalized relationship with a charismatic leader, may be more likely to show blind loyalty, obedience, and deference.

Carsten et al. (2007) examined how individuals hold divergent social constructions of followership that seem to coalesce around levels of passivity or proactivity, which followers believe could lead to effectiveness in their role. Thus, like leaders, not all followers are created equal in the minds of followers. This pattern was reflected in the work of Kelley (1992), who conceptualized followers as falling into quadrants, based on their being active or passive followers as well as whether they were critical or noncritical thinkers.

\section{Future Focus Required}

Shamir (2007) suggested that leadership effectiveness is just as much a product of good followers as it is of good leaders. Shamir (2007) made some specific recommendations for future work on follower-centered research, including examining how followers' needs, identities, and implicit theories affect leader selection and emergence as well as leader endorsement and acceptance; how follower interactions/ social networks influence the emergence of leadership and effectiveness; how followers' expectations, values, and attitudes determine leader behavior; how followers' expectations affect the leader's motivation and performance; how followers' acceptance of the leader and their support for the leader affect the leader's self-confidence, self-efficacy, and behavior; how followers' characteristics (e.g., self-concept clarity) determine the nature of the leadership relationship formed with the leader; and how followers' attitudes and characteristics (e.g., level of development) affect leader behavior. 
In addition, more work needs to be done examining how followership is construed across different industries and cultures. It is possible that in more advanced and newly forming industries, the concept of followership may be construed and enacted differently than what we might find in more established industries with long histories of treating leaders and followers in a particular way (Schyns et al. 2007).

\section{Substitutes for Leadership}

The substitutes-for-leadership theory focuses on situational factors that enhance, neutralize, and/or totally substitute for leadership. For example, a group of people engaged in electronic brainstorming using technology, such as a group decision support system, may operate as though there was a participative leader who was leading the group, but in fact, leadership comes from the operating rules for using the system to engage. Kerr \& Jermier (1978) proposed the substitutes-for-leadership theory to address some of the romance effects described above. This research stream focuses on a range of situational/organizational and follower characteristics that might influence the leadership dynamic (Howell et al. 2007).

Since this theory was originally proposed, a considerable amount of research has been completed to determine whether there are substitutes for leadership with respect to impacts on performance. A number of authors have concluded that evidence is not sufficient to support the main propositions in the theory (Dionne et al. 2002, Keller 2006). For example, Dionne et al. (2002) tested the moderating effects of task variability, organization formulation, organization inflexibility, and lack of control on the relationship between leadership behavior and group effectiveness. However, the authors found little support for the moderating effects proposed by the substitutes-for-leadership theory. This lack of support may be attributable to problems in measuring these substitutes for leadership. Yet, revisions to the scale and its use in subsequent research have not provided any further support for this theory.

\section{Future Focus Required}

Villa et al. (2003) recommended that future research consider including multiple moderators that may interact with each other to impact performance that might be erroneously attributed to the leader. Dionne et al. (2005) suggested that future research consider testing the five possible conditions linking leader behavior, leadership effectiveness, and other situational variables (e.g., substitutes), which include (a) a leadership main effects model, $(b)$ a substitutes main effect model, $(c)$ an interactive or joint effects model, $(d)$ a mediation model, wherein the substitutes mediate leadership impact versus moderate, and (e) the originally proposed moderated model. Future research should also focus more on the nature of the samples to be included in tests of substitutes for leadership. For example, one might focus on the cultural background as well as quality of one's followers by sampling professional workers who function in highly independent roles, as a possible sample for studying the boundary conditions for the effects of substitutes for leadership (Howell et al. 2007).

Finally, to evaluate fairly the substitutes for theory propositions will require more longitudinal research designs. For example, leaders who are more transformational will develop followers over time to take on more leadership roles and responsibilities. The way such leaders structure the context to develop followership and the followership itself may ultimately substitute for the leader's influence (Keller 2006).

\section{Servant Leadership}

Building on the work of Greenleaf (1991), Spears (2004) listed ten characteristics representing a servant leader: $(a)$ listening, (b) empathy, (c) healing, (d) awareness, $(e)$ persuasion, $(f)$ conceptualization, $(g)$ foresight, (h) stewardship, (i) commitment, and (j) building community. Russell \& Stone (2002) reviewed the literature on servant leadership, distinguishing such leadership into two broad categories: func- 
tional and accompany attributes. Functional attributes include having vision, being honest, trustworthy, service oriented, a role model, demonstrating appreciation of others' service, and empowerment. In terms of accompany attributes, servant leaders are described as good communicators and listeners, credible, competent, encouraging of others, teachers, and delegators. In general, the limited empirical research on servant leadership has shown that it is positively related to follower satisfaction, their job satisfaction, intrinsic work satisfaction, caring for the safety of others, and organizational commitment. Joseph \& Winston (2005) examined the relationship between employee perceptions of servant leadership and organizational trust, and reported a positive relationship with both trust in the leader as well as trust in one's organization. Washington et al. (2006) examined the relationship between servant leadership and the leader's values of empathy, integrity, competence, and agreeableness, and reported that "followers' ratings of leaders' servant leadership were positively related to followers' ratings of leaders' values of empathy, integrity, and competence" (p. 700).

\section{Future Focus Required}

One major tenet of servant leadership proposed by Greenleaf (1991) was that followers of servant leaders would be expected to become "healthier, wiser, freer, more autonomous and more likely to become servants themselves" (Barbuto \& Wheeler 2006, p. 321). This suggests that future research could take a more follower-centric approach in looking at the well-being of followers of servant leaders and the ways in which their well-being affects the ability of the leader and followers to perform. As with LMX, the measurement of servant leadership is problematic. Already many different measures of servant leadership have been proposed with scales and items varying based on problems with its definition. Future research needs to examine how the personal values of servant leaders differ from those of other leadership styles, such as transformational (Russell \& Stone 2002).

\section{Spirituality and Leadership}

One might ask leaders the question, Do you feel there is something missing in the work that you do and the way you lead others? Many authors have referred to that void and have attempted to examine how a greater sense of spirituality in the workplace may be fostered. The research on workplace spirituality also now includes a focus on spiritual leadership-defined as "comprising the values, attitudes, and behaviors that are necessary to intrinsically motivate one's self and others so that they have a sense of spiritual survival through calling and membership" (Fry 2003, p. 711).

Dent et al. (2005) examined how spirituality and leadership was defined in the literature and concluded, "The field of study is marked by all of the typical characteristics of paradigm development including a lack of consensus about a definition of workplace spirituality" (p. 626). Fry (2003) contends that spiritual leadership adds to the existing leadership literature components that have been explicitly missing, such as a sense of calling on the part of leaders and followers as well as the creation of organizational cultures characterized by altruistic love whereby leaders and followers express genuine care, concern, and appreciation for both self and others. Fry (2003) states, "The ultimate effect of spiritual leadership is to bring together or create a sense of fusion among the four fundamental forces of human existence (body, mind, heart, and spirit) so that people are motivated for high performance, have increased organizational commitment, and personally experience joy, peace, and serenity" (p. 727).

\section{Future Focus Required}

Part of the challenge in this area of leadership research is simply defining what spirituality means without necessarily tying it to one particular religion or philosophical base. Dent et al. (2005) summarized a number of definitions of spirituality that highlight some of the challenges in building theory and research in this area. The authors concluded that a wide array of concepts/ 
constructs is included in the definition of spirituality, but some of the common elements are a search for meaning, reflection, an inner connection, creativity, transformation, sacredness, and energy.

Fry (2005) defines spiritual leadership as comprising the values, attitudes, and behaviors that are necessary to intrinsically motivate self and others to enhance a sense of spiritual survival through calling and membership. Yet, some authors criticize Fry's model as well as other models of spirituality and leadership for not providing a sufficient understanding of what constitutes spirituality and the ways in which it ties to leadership. For example, Benefiel (2005) criticized the work on spirituality and leadership, stating that it "inadvertently draws upon outdated, discredited, or shallow approaches to spirituality; they reinvent the wheel; they dip into credible theories of spirituality but then don't fully develop them or resolve the conflicts among them. While these theories are comprehensive and creative in the context of leadership studies, a more robust, up-to-date, and sophisticated understanding of spirituality is needed if theories of spiritual leadership are to stand up under scrutiny and be taken seriously in the wider academy" (p. 727). Finally, there still seem to be two schools of thought in this area of leadership research: In one school, a set of scholars discuss spirituality in the theological sense (Whittington et al. 2005), whereas in the other school,

Cross-cultural leadership: the examination of leadership in multicultural contexts
GLOBE: global leadership and organizational behavioral effectiveness the focus is more on understanding the inner motivation and drive a leader creates in followers to enhance workplace spirituality (Fry 2005). Until a definition of what constitutes spirituality and leadership is agreed upon, it will be difficult to conceptualize and measure these constructs.

\section{Cross-Cultural Leadership}

Although most leadership research and theory has been developed and tested within a Western context, a growing interest in research and theory focuses on the role of leadership across cultural contexts.
This interest is driven in part by the globalization of organizations that encourage and, at times, require leaders to work from and across an increasingly diverse set of locations. The result is an increased focus on cross-cultural leadership research (Gelfand et al. 2007, House et al. 2004). Extensive reviews also exist for cross-cultural research that is more tangentially linked to leadership (Hofstede 2001, Kirkman et al. 2006, Leung et al. 2005).

\section{Project GLOBE}

Although there have been numerous critiques and discussions of work in this area (see Journal of International Business Studies, Vol. 37, No. 6), the work of Project GLOBE (global leadership and organizational behavioral effectiveness) constitutes one of the more ambitious and influential cross-cultural leadership studies. The study, as detailed in an edited book (House et al. 2004), involved a group of more than 160 researchers working in 62 societies. Research included a mix of quantitative and qualitative investigations. The study was designed to address a number of goals, the first of which was to develop cultural dimensions at both the organizational and societal level of analysis, building upon the work of Hofstede (2001). A second major goal of the project was to examine the beliefs that different cultures had about effective leaders. Although many of the leadership attributes and behaviors examined varied by culture, the research did determine that certain implicit leadership theories (e.g., charisma/transformational, team-oriented) had universal endorsement. A third phase of the research involved ethnographies of individual countries based largely on qualitative data.

\section{Global Leadership}

The goal of identifying leaders who are able to effectively lead across a variety of cultures has great appeal and has been the focus of numerous articles in both the academic (Mobley et al. 1999) and popular press (Goldsmith 2003, Green et al. 2003, 
Lane 2004). However, substantial differences and approaches remain in how global leadership is conceptualized and defined. One approach primarily focuses on international experience, implying that leaders must spend time living in different cultures in order to be prepared to lead (Van Dyne \& Ang 2006). A second approach emphasizes the competencies a leader needs to have in order to lead effectively and successfully across cultures (Mendenhall 2001). This approach emphasizes having a broad set of experiences and competencies that allow leaders to manage across cultures rather than focusing on a deep knowledge of one or two specific cultures. This approach is reflected in the related work on global mindset (Boyacigiller et al. 2004, Clapp-Smith et al. 2007) and cultural intelligence (Earley et al. 2007, Thomas 2006).

\section{Comparative Leadership}

Comparative research on the effectiveness of leadership in different cultures was the basis of early work in this field and continues to be a major area of research (Dickson et al. 2003, Dorfman 2004, Gelfand et al. 2007, Kirkman et al. 2006). Such research compares leadership in two or more cultures, examining the degree to which a practice that was developed in one culture applies to others. A common approach examines the direct impact a cultural dimension has on leadership. For example, one major cross-cultural study examined the impact of cultural values on the selection of sources of guidance for dealing with work events that managers are likely to face in 47 countries (Smith et al. 2002). This study identified which sources of guidance were correlated with specific cultural dimensions using several major cultural value dimension frameworks.

Another common strategy examines the indirect influence of culture as it moderates the relationship between leadership practice and relevant performance outcomes. Walumbwa et al. (2007) examined the effect of allocentrism (collective orientation) and idiocentrism (individual orientation) on the relationships among leadership (transformational and transactional) and both or- ganizational commitment and satisfaction with supervisor. Allocentrics were found to react more positively to transformational leaders, whereas idiocentrics had a more positive reaction to transactional leaders.

\section{Future Focus Required}

Although significant progress has been made in the cross-cultural leadership literature, several important issues need to be addressed. For example, the term "culture" itself refers to a complex set of constructs around which there is ongoing debate. Not surprisingly, the attempt to examine the effect that culture has on leadership brings with it the associated conceptual and methodological challenges that are already associated with cross-cultural research (Van de Vijver \& Leung 2000). Despite improvements made over the years, a need remains for future research to focus on levels of analysis when conducting cross-cultural leadership research. This applies to the development of explicitly cross-level theoretical models as well as the use of appropriate statistical techniques. Although the relevance of levels is widely recognized, the implications of cross-level analysis are often not reflected in the research design in this literature, particularly when it comes to insuring a sufficient number of cultures are included to conduct the analysis. Many researchers assume they can use the country as a convenient substitute for measuring culture, which may be an erroneous level of analysis given the diversity of cultures represented in most countries. Large-scale collaborations such as the GLOBE (House et al. 2004) study and the 47-nation study of Smith et al. (2002) are likely to be required to develop the types of samples needed for such analytical approaches.

\section{E-Leadership}

Leading virtually involves leading people from different departments, organizations, countries, and sometimes even competitor companies (Avolio et al. 2001). In virtual teams, "challenges are more likely to 
E-leadership: leadership where individuals or groups are geographically dispersed and interactions are mediated by technology occur when distributed work occurs in different time zones, when local communication and human infrastructures fail, when team members' hardware and software platforms are different, or when local work demands require the immediate attention of collocated managers and workers, thereby creating pressure to pursue local priorities over the objectives of distant collaborators" (A. Weisband 2008b, p. 6).

Zigurs (2003) suggested that traditional leadership models built on a foundation of face-to-face interactions may not fully explain how virtual leadership and teams work. Specifically, how one provides feedback, encouragement, rewards, and motivation needs to be re-examined where leadership is mediated through technology. Zigurs (2003) suggests that the continuing development in technology such as increased bandwidth, wireless networks, integrated handheld devices, voice input, built-in video, video walls, and automatic translation will no doubt have a significant impact on how virtual teams communicate and how leadership is manifested in such teams. To date, a great deal of the work on e-leadership focuses on either leadership in virtual work teams or groups interacting in what are called "group decision support systems." For example, Zaccaro \& Bader (2003) provided an overview of the similarities and differences between face-to-face teams and e-teams. They specifically focused on the impact of leadership functions such as communication building, role clarification, team development, and effective task execution and how they differed when mediated through technology. Other authors have focused on the effects of structural factors such as distance and multiple locations on e-leadership and virtual team effectiveness (e.g., Cascio \& Shurygailo 2003).

\section{Common Questions with E-Leadership}

Some of the common questions or hypotheses suggested to guide research on e-leadership and virtual teams have been summarized by Avolio et al. (2001), Barelka (2007), as well as Ahuja \& Galvin (2003) and include the following: How does the nature and structure of technology impact how leadership style influences follower motivation and performance? What effect will leadership mediated through technology have on trust formation? Will the nature of the technology such as its richness or transparency be a factor in building trust in virtual teams? How will the leadership and location of teams and technology connecting members affect the quality and quantity of their communication? How will the nature of the task and its complexity influence how leadership affects virtual team performance?

\section{Group and Virtual Teams Research}

A number of studies have examined eleadership and virtual teams. For example, Kahai \& Avolio (2008) investigated the effects of leadership style and anonymity on the discussion of an ethical issue in an electronic system context. Kahai \& Avolio examined how groups discussed an ethical issue by manipulating the leadership style of the target e-leader and whether the group members were anonymous or identified. They reported that frequency of group member participation in discussing how to address the ethical issue was greater when leadership style was transactional versus transformational.

Xiao et al. (2008) conducted a field experiment focusing on surgical teams operating in a real-life trauma center. In their study, the team leader either was placed in the room with the surgical team or interacted with them virtually. The authors reported that when the team leader was in the next room, the leader had greater influence on communications between the senior member in the room and other team members. However, when the senior leader was collocated, the amount of communication between the team leader, the senior member, and junior members was more balanced. With high task urgency, the team leader was more involved with the senior team member in terms of communication regardless of location, whereas the communication between the team leader and junior members was reduced. 
Balthazard et al. (2008) examined the mediational role of leadership and group member interaction styles in comparing virtual and face-to-face teams. They reported that group members in face-to-face teams were generally more cohesive, were more accepting of a group's decisions, and exhibited a greater amount of synergy than did virtual teams. Face-to-face teams exhibited a greater amount of constructive interaction in comparison with virtual teams, which scored significantly higher on defensive interaction styles.

Malhotra et al. (2007) collected survey, interview, and observational data on virtual teams to identify the leadership practices of effective leaders of virtual teams. These leadership practices included the ability to (a) establish and maintain trust through the use of communication technology, $(b)$ ensure that distributed diversity is understood and appreciated, (c) manage effectively virtual work-life cycles, $(d)$ monitor team progress using technology, (e) enhance visibility of virtual members within the team and outside the organization, and $(f)$ let individual team members benefit from the team.

\section{Future Focus Required}

Hambley et al. (2006) advocate that future research on e-leadership be conducted in field settings. They recommend that virtual teams working on actual problem-solving tasks and projects be examined to help capture the motivational element that may not exist with ad hoc groups working in the lab. A. Weisband (2008a) argued, "Future research may want to consider how we lead in environments that lack any central coordination mechanism, or how multiple leaders work together to innovate, create, and help others" (p. 255).

E-leadership areas recommended for future research by authors of papers on the virtual team topic include task ownership, cohesion, media richness (i.e., technology's capacity for providing immediate feedback, the number of cues and channels utilized, personalization of messages, and language variety), communica- tion quality, asynchronous and synchronous communication, task complexity, and working on multiple virtual teams simultaneously (Kozlowski \& Bell 2003, Zaccaro $\&$ Bader 2003). For example, Watson et al. (1993) studied culturally diverse and homogenous virtual groups and compared their interactions over a 17 -week period. They found that culturally diverse groups initially suffered in their performance but over time surpassed homogenous groups, especially in terms of the number of alternative ideas generated.

In summary, we expect that the work on virtual leadership and team interactions will continue to be a growth area for leadership research. The fundamental issue for leadership scholars and practitioners to address is how technology is transforming the traditional roles of leadership at both individual and collective levels by examining "how existing leadership styles and cultures embedded in a group and/or organization affect the appropriation of advanced information technology systems" (Avolio et al. 2001, p. 658).

\section{Closing Comments and Integration}

The evolution of this literature points to several important trends. The first trend involves the field of leadership taking a more holistic view of leadership. Specifically, researchers are now examining all angles of leadership and including in their models and studies the leader, the follower, the context, the levels, and their dynamic interaction. The second trend involves examining how the process of leadership actually takes place by, for example, integrating the work of cognitive psychology with strategic leadership. In this regard, we are witnessing greater interest in how the leader processes information as well as how the follower does so, and how each affects the other, the group, and organization. More work is expected on examining the various mediators and moderators that help to explain how leadership influences intended outcomes. A third trend involves deriving alternative ways to examine leadership. We 
expect to see a greater use of mixed-methods designs in future research. The quantitative strategies for studying leadership have dominated the literature over the past 100 years, but increasing attention is being paid to cases and qualitative research that should now be integrated with quantitative approaches.

Part of the evolution of leadership theory and research will continue to involve further defining what actually constitutes leadership from a content perspective, e.g., authentic, transformational, or visionary, and a process perspective, e.g., shared, complex, or strategic. We also expect much more attention to be paid to the area of strategic leadership, which we did not have space here to cover, and applying what we have learned about content and process to this level of analysis. Finally, we go back to the point where we started in suggesting that the time has never been better to examine the genuine development of leadership. The field of leadership has done surprisingly little to focus its energies on what contributes to or detracts from genuine leadership development. Given the forces in the global market, we expect that over the next 10 years, research and theory in this area will explode as organizations increasingly ask for ways to accelerate positive leadership development as they enter the front lines of the war for leadership talent.

In summary, the leadership field over the past decade has made tremendous progress in uncovering some of the enduring mysteries associated with leadership. These include whether leaders are born or made, how followers affect how successful leaders can be, how some charismatic leaders build up societies and others destroy them, as well as what impact leading through technology has on individual and collective performance. The period that leadership theory and research will enter over the next decade is indeed one of the most exciting in the history of this planet.

\section{Summary Points}

1. The field of leadership is evolving to a more holistic view of leadership.

2. More positive forms of leadership are being integrated into literature.

3. Increasing attention is being given to examining how leadership causally impacts interim and ultimate outcomes.

4. The follower is becoming an integral part of the leadership dynamic system.

5. There is growing interest in what genuinely develops leadership.

6. E-leadership is becoming a commonplace dynamic in work organizations.

7. More and more leadership is being distributed and shared in organizations.

8. Leadership is being viewed as a complex and emergent dynamic in organizations.

\section{Future Issues}

1. More future research in leadership will be mixed methods.

2. Determining the causal mechanisms that link leadership to outcomes will be a priority.

3. Assessing and developing leadership using evidence-based strategies will be a target focus.

4. Examining strategic leadership as a process and person will be an evolving area of theory and research.

5. More theoretical work and research will focus on the follower as a prime element in the leadership dynamic.

6. How to develop global mindsets among leaders will be an area of interest.

7. A top priority area will be leadership in cultures that are underrepresented in the literature, such as Muslim cultures.

8. How shared leadership evolves and develops will be a focus in face-to-face and virtual environments. 


\section{Acknowledgments}

We greatly appreciate the contributions made to this paper by Melissa Carsten, Rachel Clapp-Smith, Jakari Griffith, Yongwoon Kim, Ketan Mhatre, David Sweetman, Mary Uhl-Bien, and Kay-Ann Willis.

\section{Literature Cited}

Adebayo DO, Udegbe IB. 2004. Gender in the boss-subordinate relationship: a Nigerian study. J. Organ. Behav. 25:515-25

Agle BR, Nagarajan NJ, Sonnenfeld JA, Srinivasan D. 2006. Does CEO charisma matter? An empirical analysis of the relationships among organizational performance, environmental uncertainty, and top management team perceptions of CEO charisma. Acad. Manage. J. 49:161-74

Ahuja MK, Galvin JE. 2003. Socialization in virtual groups. J. Manage. 29:161-85

Altrocchi J. 1999. Individual differences in pluralism in self-structure. In The Plural Self: Multiplicity in Everyday Life, ed. J Rowan, M Cooper, pp. 168-82. London: Sage

Arvey RD, Zhang Z, Avolio BJ, Krueger RF. 2007. Developmental and genetic determinants of leadership role occupancy among women. J. Appl. Psychol. 92:693-706

Avolio BJ. 1999. Full Leadership Development: Building the Vital Forces in Organizations. Thousand Oaks, CA: Sage. 234 pp.

Avolio BJ. 2005. Leadership Development in Balance: Made/Born. Hillsdale, NJ: Erlbaum

Avolio BJ. 2007. Promoting more integrative strategies for leadership theory-building. Am. Psychol. 62:25-33

Avolio BJ, Bass BM. 1995. Individual consideration viewed at multiple levels of analysis - a multilevel framework for examining the diffusion of transformational leadership. Leadersh. Q. 6:199-218

Avolio BJ, Bass BM, Walumbwa FO, Zhu W. 2004a. Multifactor Leadership Questionnaire: Manual and Sampler Test. Redwood City, CA: Mind Garden

Avolio BJ, Chan A. 2008. The dawning of a new era for genuine leadership devel- opment. In International Review of Industrial and Organizational Psychology, ed. G Hodgkinson, K Ford, pp. 197-238. New York: Wiley

Avolio BJ, Gardner WL. 2005. Authentic leadership development: getting to the root of positive forms of leadership. Leadersh. $Q$. 16:315-38

Avolio BJ, Hannah S, Reichard R, Chan A, Walumbwa F. 2009. 100 years of leadership intervention research. Leadersh. $Q$. In press

Avolio BJ, Kahai SS, Dodge GE. 2001. E-leadership: implications for theory, research, and practice. Leadersh. Q. 11:615-68

Avolio BJ, Luthans F. 2006. The High Impact Leader: Moments Matter in Accelerating Authentic Leadership. New York: McGrawHill. 273 pp.

Avolio BJ, Zhu WC, Koh W, Bhatia P. 2004b. Transformational leadership and organizational commitment: mediating role of psychological empowerment and moderating role of structural distance. J. Organ. Behav. 25:951-68

Balthazard PA, Waldman DA, Atwater LE. 2008. The mediating effects of leadership and interaction style in face-to-face and virtual teams. See S Weisband 2008, pp. 127-50

Barbuto JE, Wheeler DW. 2006. Scale development and construct clarification of servant leadership. Group Organ. Manage. 31:300-26

Barelka AJ. 2007. New findings in virtual team leadership. Unpubl. PhD thesis. Mich. State Univ.

Bass BM. 1985. Leadership and Performance Beyond Expectations. New York: Free Press. $256 \mathrm{pp}$.

Bass BM, Avolio BJ, Jung DI, Berson Y. 2003. Predicting unit performance by assessing transformational and transactional leadership. J. Appl. Psychol. 88:207-18

Bass BM, Bass R. 2008. Handbook of Leadership: Theory, Research, and Application. New York: Free Press. 1296 pp.

Bass BM, Steidlmeier P. 1999. Ethics, character, and authentic transformational leadership behavior. Leadersh. Q. 10:181-217

Benefiel M. 2005. The second half of the journey: spiritual leadership for orga- 
nizational transformation. Leadersh. $Q$. 16:723-47

Bligh MC, Kohles JC, Pearce CL, Justin JEG, Stovall JF. 2007. When the romance is over: follower perspectives of aversive leadership. Appl. Psychol.: Int. Rev. Psychol. Appl. Rev. Int. 56:528-57

Bono JE, Anderson MH. 2005. The advice and influence networks of transformational leaders. J. Appl. Psychol. 90:1306-14

Bono JE, Ilies R. 2006. Charisma, positive emotions and mood contagion. Leadersh. Q. 17:317-34

Bono JE, Judge TA. 2003. Self-concordance at work: toward understanding the motivational effects of transformational leaders. Acad. Manage. J. 46:554-71

Boyacigiller NA, Beechler S, Taylor S, Levy O. 2004. The crucial yet elusive global mindset. In Handbook of Global Management: A Guide to Managing Complexity, ed. J McNett, pp. 81-93. Malden, MA: Blackwell Sci.

Brown ME, Trevino LK, Harrison DA. 2005. Ethical leadership: a social learning perspective for construct development and testing. Organ. Behav. Hum. Decis. Process. 97:117-34

Bryman A. 1992. Charisma and Leadership in Organizations. London/Newbury Park, CA: Sage. 198 pp.

Burns JM. 1978. Leadership. New York: Harper \& Row. 530 pp.

Campbell JD, Assanand S, Di Paula A. 2003. The structure of the self-concept and its relation to psychological adjustment. J. Personal. 71:115-40

Carson JB, Tesluk PE, Marrone JA. 2007. Shared leadership in teams: an investigation of antecedent conditions and performance. Acad. Manage. J. 50:1217-34

Carsten M, Uhl-Bien M, Patera J, West B, McGregor R. 2007. Social Constructions of Followership. Presented at Acad. Manag. Conf., Philadelphia, PA

Cascio WF, Shurygailo S. 2003. E-leadership and virtual teams. Organ. Dyn. 31:362-76

Chen GQ, Tjosvold D, Liu CH. 2006. Cooperative goals, leader people and productivity values: their contribution to top management teams in China. J. Manage. Stud. 43:1177-200
Clapp-Smith R, Luthans F, Avolio BJ. 2007. The role of psychological capital in global mindset development. In The Global Mindset: Advances in International Management, ed. MA Hitt, R Steers, M Javidan, pp. 105-30. Greenwich, CT: JAI

Cogliser CC, Schriesheim CA. 2000. Exploring work unit context and leader-member exchange: a multi-level perspective. J. Organ. Behav. 21:487-511

Colella A, Varma A. 2001. The impact of subordinate disability on leader-member exchange relationships. Acad. Manage. J. 44:304-15

Conger JA, Kanungo RN. 1998. Charismatic Leadership in Organizations. Thousand Oaks, CA: Sage. 288 pp.

Cooper CD, Scandura TA, Schriesheim CA. 2005. Looking forward but learning from our past: potential challenges to developing authentic leadership theory and authentic leaders. Leadersh. Q. 16:475-93

Day DV, Gronn P, Salas E. 2004. Leadership capacity in teams. Leadersh. Q. 15:857-80

De Cremer D, van Knippenberg D. 2004. Leader self-sacrifice and leadership effectiveness: the moderating role of leader self-confidence. Organ. Behav. Hum. Decis. Process. 95:140-55

Dent EB, Higgins AE, Wharff DM. 2005. Spirituality and leadership: an empirical review of definitions, distinctions, and embedded assumptions. Leadersh. $Q$. 16:625-53

Dickson MW, Den Hartog DN, Mitchelson JK. 2003. Research on leadership in a cross-cultural context: making progress, and raising new questions. Leadersh. $Q$. 14:729-68

Dionne SD, Yammarino FJ, Atwater LE, James LR. 2002. Neutralizing substitutes for leadership theory: leadership effects and common-source bias. J. Appl. Psychol. 87:454-64

Dionne SD, Yammarino FJ, Howell JP, Villa J. 2005. Substitutes for leadership, or not. Leadersh. Q. 16:169-93

Dooley KJ, Lichtenstein B. 2008. Research methods for studying the dynamics of leadership. In Complexity Leadership, Part I: Conceptual Foundations, ed. M Uhl-Bien, R Marion, pp. 269-90. Charlotte, NC: Inform. Age 
Dorfman P. 2004. International and crosscultural leadership research. In Handbook for International Management Research, ed. BJ Punnett, O Shenkar, pp. 265-355. Ann Arbor, MI: Univ. Mich. Press

Dvir T, Shamir B. 2003. Follower developmental characteristics as predicting transformational leadership: a longitudinal field study. Leadersh. Q. 14:327-44

Dweck CS. 1986. Motivational processes affecting learning. Am. Psychol. 41:1040-48

Earley CP, Murnieks C, Mosakowski E. 2007. Cultural intelligence and the global mindset. In The Global Mindset, ed. M Javidan, RM Steers, MA Hitt, pp. 75-103. New York: Elsevier

Epitropaki O, Martin R. 2005. From ideal to real: a longitudinal study of the role of implicit leadership theories on leadermember exchanges and employee outcomes. J. Appl. Psychol. 90:659-76

Erdogan B, Liden R. 2002. Social exchanges in the workplace: a review of recent developments and future research directions in leader-member exchange theory. In Leadership, ed. IL Neider, CA Schriesheim, pp. 65-114. Greenwich, CT: Information Age

Follett MP. 1924. Creative Experience. New York: Logmans Green

Fredrickson BL. 2001. The role of positive emotions in positive psychology-the broaden-and-build theory of positive emotions. Am. Psychol. 56:218-26

Fry LW. 2003. Toward a theory of spiritual leadership. Leadersh. Q. 14:693-727

Fry LW. 2005. Introduction to The Leadership Quarterly special issue: toward a paradigm of spiritual leadership. Leadersh. $Q$. 16:619-22

Gelfand MJ, Erez M, Aycan Z. 2007. Crosscultural organizational behavior. Annu. Rev. Psychol. 58:479-514

George B. 2003. Authentic Leadership: Rediscovering the Secrets to Creating Lasting Value. San Francisco, CA: Jossey-Bass. 217 pp.

Gerstner CR, Day DV. 1997. Meta-analytic review of leader-member exchange theory: correlates and construct issues. J. Appl. Psychol. 82:827-44

Goethals GR. 2005. Presidential leadership. Annu. Rev. Psychol. 56:545-70
Goldsmith M. 2003. Global Leadership: The Next Generation. Upper Saddle River, NJ: Financial Times Prentice Hall. 350 pp.

Graen GB. 2006. In the eye of the beholder: cross-cultural lesson in leadership from project GLOBE: a response viewed from the third culture bonding (TCB) model of cross-cultural leadership. Acad. Manage. Perspect. 20:95-101

Graen GB, Uhl-Bien M. 1995. Relationshipbased approach to leadership -development of leader-member exchange (LMX) theory of leadership over 25 years - applying a multilevel multidomain perspective. Leadersh. Q. 6:219-47

Green S, Hassan F, Immelt J, Marks M, Meiland D. 2003. In search of global leaders. Harvard Bus. Rev. 81:38-45

Greenleaf RK. 1991. The Servant as Leader. Indianapolis, IN: Robert Greenleaf Center

Hackman JR, Wageman R. 2005. A theory of team coaching. Acad. Manage. Rev. 30:269-87

Hambley LA, O'Neil TA, Kline TJB. 2006. Virtual team leadership: the effects of leadership style and communication medium on team interaction styles and outcomes. Organ. Behav. Hum. Decis. Process. 103:1-20

Harter JK, Schmidt FL, Hayes TL. 2002. Business-unit-level relationship between employee satisfaction, employee engagement, and business outcomes: a meta-analysis. J. Appl. Psychol. 87:268-79

Hazy JK, Goldstein JA, Lichtenstein BB. 2007. Complex systems leadership theory: an introduction. In Complex Systems Leadership Theory: New Perspectives from Complexity Science on Social and Organizational Effectiveness, ed. JK Hazy, JA Goldstein, BB Lichtenstein, pp. 1-13. Mansfield, MA: ISCE Publ.

Hofstede GH. 2001. Culture's Consequences: Comparing Values, Behaviors, Institutions, and Organizations Across Nations. Thousand Oaks, CA: Sage. 596 pp.

Hogg MA, Martin R, Weeden K. 2004. Leader-member relations and social identity. In Leadership and Power: Identity Processes in Groups and Organizations, ed. D van Knippenberg, MA Hogg, pp. 18-33. London: Sage 
House RJ, Hanges PJ, Javidan M, Dorfman PW, Gupta V. 2004. Culture, Leadership, and Organizations: The GLOBE Study of 62 Societies. Thousand Oaks, CA: Sage. 818 pp.

Howell JM, Shamir B. 2005. The role of followers in the charismatic leadership process: relationships and their consequences. Acad. Manage. Rev. 30:96-112

Howell JP, Bowen DE, Dorfman PW, Kerr S, Podsakoff PM. 2007. Substitutes for leadership: effective alternatives to ineffective leadership. In Leadership: Understanding the Dynamics of Power and Influence in Organizations, ed. RP Vecchio, pp. 363-76. Notre Dame, IN: Univ. Notre Dame Press

Ilies R, Nahrgang JD, Morgeson FP. 2007. Leader-member exchange and citizenship behaviors: a meta-analysis. J. Appl. Psychol. 92:269-77

Joseph EE, Winston BE. 2005. A correlation of servant leadership, leader trust, and organizational trust. Leadersh. Organ. Dev. J. 26:6-22

Judge TA, Piccolo RF. 2004. Transformational and transactional leadership: a meta-analytic test of their relative validity. J. Appl. Psychol. 89:755-68

Kacmar KM, Zivnuska S, White CD. 2007. Control and exchange: the impact of work environment on the work effort of low relationship quality employees. Leadersh. Q. 18:69-84

Kahai SS, Avolio BJ. 2008. Effects of leadership style and anonymity on the discussion of an ethical issue in an electronic meeting system context. See S Weisband 2008, pp. 97-126

Kark R, Van Dijk D. 2007. Motivation to lead, motivation to follow: the role of the selfregulatory focus in leadership processes. Acad. Manage. Rev. 32:500-28

Keller RT. 2006. Transformational leadership, initiating structure, and substitutes for leadership: a longitudinal study of research and development project team performance. J. Appl. Psychol. 91:202-10

Kelley RE. 1992. The Power of Followership: How to Create Leaders People Want to Follow, and Followers Who Lead Themselves. New York: Doubleday/Currency. 260 pp.
Kerr S, Jermier JM. 1978. Substitutes for leadership: their meaning and measurement. Organ. Behav. Hum. Perform. 22:376-403

Kirkman BL, Lowe KB, Gibson CB. 2006. A quarter century of Culture's Consequences: a review of empirical research incorporating Hofstede's cultural values framework. J. Int. Bus. Stud. 37:285-320

Kozlowski SWJ, Bell BS. 2003. Work groups and teams in organizations. In Handbook of Psychology: Industrial and Organizational Psychology, ed. WC Borman, DR Ilgen, RJ Klimoski, pp. 333-75. London: Wiley

Kulich C, Ryan MK, Haslam SA. 2007. Where is the romance for women leaders? The effects of gender on leadership attributions and performance-based pay. Appl. Psychol. Int. Rev. Psychol. Appl. Rev. Int. 56:582-601

Lane HW. 2004. The Blackwell Handbook of Global Management: A Guide to Managing Complexity. New York: Wiley-Blackwell. $476 \mathrm{pp}$.

Leung K, Bhagat RS, Buchan NR, Erez M, Gibson CB. 2005. Culture and international business: recent advances and their implications for future research. J. Int. Bus. Stud. 36:357-78

Liao H, Chuang AC. 2007. Transforming service employees and climate: a multilevel, multisource examination of transformational leadership in building long-term service relationships. J. Appl. Psychol. 92:1006-19

Lichtenstein BB, Uhl-Bien M, Marion R, Seers A, Orton JD, Schreiber C. 2007. Complexity leadership theory: an interactive perspective on leading in complex adaptive systems. In Complex Systems Leadership Theory: New Perspectives from Complexity Science on Social and Organizational Effectiveness, ed. JK Hazy, JA Goldstein, BB Lichtenstein, pp. 129-41. Mansfield, MA: ISCE Publ.

Lord RG, Brown BR. 2004. Leadership Processes and Follower Self-Identity. Hillsdale, NJ: Erlbaum

Lord RG, Brown DJ. 2001. Leadership, values, and subordinate self-concepts. Leadersh. Q. 12:133-52

Lord RG, Brown DJ, Harvey JL, Hall RJ. 2001. Contextual constraints on prototype gen- 
eration and their multilevel consequences for leadership perceptions. Leadersh. $Q$. 12:311-38

Lord RG, Emrich CG. 2000. Thinking outside the box by looking inside the box: extending the cognitive revolution in leadership research. Leadersh. Q. 11:551-79

Lord RG, Hall RJ. 1992. Contemporary views of leadership and individual differences. Leadersh. Q. 3:137-57

Lord RG, Hall RJ. 2005. Identity, deep structure and the development of leadership skill. Leadersh. Q. 16:591-615

Lowe KB, Gardner WL. 2000. Ten years of the Leadership Quarterly: contributions and challenges for the future. Leadersh. $Q$. 11:459-514

Luthans F. 2002. Positive organizational behavior: developing and managing psychological strengths. Acad. Manage. Exec. 16:57-72

Luthans F, Avolio BJ. 2003. Authentic leadership: a positive developmental approach. In Positive Organizational Scholarship: Foundations of a New Discipline, ed. KS Cameron, JE Dutton, RE Quinn, pp. 241-58. San Francisco, CA: Berrett-Koehler

Malhotra A, Majchrzak A, Rosen B. 2007. Leading virtual teams. Acad. Manage. Perspect. 21:60-70

Martin R, Thomas G, Charles K, Epitropaki O, McNamara R. 2005. The role of leadermember exchanges in mediating the relationship between locus of control and work reactions. J. Occup. Organ. Psychol. 78:141-47

Maurer TJ, Lippstreu M. 2005. Differentiating Motivation to Lead from Motivation to Develop Leadership Capability: Relevance of "Born vs Made" Beliefs. Presented at meet. Acad. Manage., Honolulu, HI

Meindl JR, Ehrlich SB, Dukerich JM. 1985. The romance of leadership. Adm. Sci. $Q$. 30:78-102

Mendenhall ME. 2001. Introduction: new perspectives on expatriate adjustment and its relationship to global leadership development. In Developing Global Business Leaders: Policies, Processes, and Innovations, ed. GK Stahl, pp. 1-16. Westport, CT: Quorum
Mobley WH, Gessner MJ, Arnold V. 1999. Advances in Global Leadership. Stamford, CT: JAI

Mumford MD, Connelly S, Gaddis B. 2003. How creative leaders think: experimental findings and cases. Leadersh. $Q$. 14:411-32

Mumford MD, Friedrich TL, Caughron JJ, Byrne CL. 2007. Leader cognition in realworld settings: How do leaders think about crises? Leadersh. Q. 18:515-43

O'Connor PMG, Quinn L. 2004. Organizational capacity for leadership. In The Center for Creative Leadership Handbook of Leadership Development, ed. CD McCauley, E Van Velsor, pp. 417-37. San Francisco, CA: Jossey-Bass

Pearce CL. 2004. The future of leadership: combining vertical and shared leadership to transform knowledge work. Acad. Manage. Exec. 18:47-57

Pearce CL, Conger JA. 2003. Shared Leadership: Reframing the Hows and Whys of Leadership. Thousand Oaks, CA: Sage

Pearce CL, Sims HP. 2002. The relative influence of vertical vs. shared leadership on the longitudinal effectiveness of change management teams. Group Dynamics Theory Res. Pract. 6:172-97

Piccolo RF, Colquitt JA. 2006. Transformational leadership and job behaviors: the mediating role of core job characteristics. Acad. Manage. J. 49:327-40

Plowman DA, Duchon D. 2008. Dispelling the myths about leadership: from cybernetics to emergence. In Complexity Leadership Part I: Conceptual Foundations, ed. M Uhl-Bien, R Marion, pp. 129-53. Charlotte, NC: Inform. Age

Reichard RJ, Avolio BJ. 2005. Where are we? The status of leadership intervention research: a meta-analytic summary. In $A u$ thentic Leadership and Practice: Origins, Effects, and Development, ed. WL Gardner, BJ Avolio, FO Walumbwa, pp. 203-26. Oxford, UK: Elsevier Sci.

Roberts LM, Dutton JE, Spreitzer CM, Heaphy ED, Quinn RE. 2005. Composing the reflected best-self portrait: building pathways for becoming extraordinary in work organizations. Acad. Manage. Rev. 30:712-36 
Russell RF, Stone AG. 2002. A review of servant leadership attributes: developing a practical model. Leadersh. Organ. Dev. J. 23:145-57

Schaubroeck J, Lam SSK, Cha SE. 2007. Embracing transformational leadership: team values and the impact of leader behavior on team performance. J. Appl. Psychol. 92:1020-30

Schriesheim CA, Castro SL, Cogliser CC. 1999. Leader-member exchange (LMX) research: a comprehensive review of theory, measurement, and data-analytic practices. Leadersh. Q. 10:63-113

Schyns B, Felfe J, Blank H. 2007. Is charisma hyper-romanticism? Empirical evidence from new data and a meta-analysis. Appl. Psychol. Int. Rev. Psychol. Appl. Rev. Int. 56:505-27

Shamir B. 2007. From passive recipients to active coproducers: followers' roles in the leadership process. In Follower-Centered Perspectives on Leadership: A Tribute to the Memory of James R. Meindl, ed. B Shamir, R Pillai, MC Bligh, M Uhl-Bien, pp. ixxxxix. Greenwich, CT: Inform. Age

Smith PB, Peterson MF, Schwartz SH, Ahmad AH, Akande D, et al. 2002. Cultural values, sources of guidance, and their relevance to managerial behaviora 47-nation study. J. Cross Cult. Psychol. 33:188-208

Sosik JJ, Avolio BJ, Kahai SS. 1997. Effects of leadership style and anonymity on group potency and effectiveness in a group decision support system environment. J. Appl. Psychol. 82:89-103

Sparrowe RT. 2005. Authentic leadership and the narrative self. Leadersh. Q. 16:419-39

Sparrowe RT, Soetjipto BW, Kraimer ML. 2006. Do leaders' influence tactics relate to members' helping behavior? It depends on the quality of the relationship. Acad. Manage. J. 49:1194-208

Spears LC. 2004. The understanding and practice of servant leadership. In Practicing Servant-Leadership: Succeeding Through Trust, Bravery, and Forgiveness, ed. LC Spears, M Lawrence, pp. 167-200. San Francisco, CA: Jossey-Bass

Swann WB, Chang-Schneider C, McClarty KL. 2007. Do people's self-views matter?
Self-concept and self-esteem in everyday life. Am. Psychol. 62:84-94

Tekleab AG, Taylor MS. 2003. Aren't there two parties in an employment relationship? Antecedents and consequences of organization-employee agreement on contract obligations and violations. J. Organ. Behav. 24:585-608

Thomas DC. 2006. Domain and development of cultural intelligence - the importance of mindfulness. Group Organ. Manage. 31:78-99

Tosi HL, Misangyi VF, Fanelli A, Waldman DA, Yammarino FJ. 2004. CEO charisma, compensation, and firm performance. Leadersh. Q. 15:405-20

Uhl-Bien M. 2006. Relational leadership theory: exploring the social processes of leadership and organizing. Leadersh. $Q$. 17:654-76

Uhl-Bien M, Graen GB, Scandura TA. 2000. Implications of leader-member exchange (LMX) for strategic human resource management systems: relationships as social capital for competitive advantage. Res. Pers. Hum. Resour. Manage. 18:137-85

Uhl-Bien M, Marion R. 2008. Complexity Leadership. Charlotte, NC: Information Age

Uhl-Bien M, Marion R, McKelvey B. 2007. Complexity leadership theory: shifting leadership from the Industrial Age to the Knowledge Era. Leadersh. Q. 18:298-318

Van de Vijver FJR, Leung K. 2000. Methodological issues in psychological research on culture. J. Cross-Cultural Psychol. 31:33-51

Van Dyne L, Ang S. 2006. Getting more than you expect: global leader initiative to span structural holes and reputational effectiveness. In Advances in Global Leadership, ed. WH Mobley, E Weldon, pp. 10122. New York: Elsevier

Villa JR, Howell JP, Dorfman PW, Daniel DL. 2003. Problems with detecting moderators in leadership research using moderated multiple regression. Leadersh. $Q$. 14:3-23

Waldman DA, Javidan M, Varella P. 2004. Charismatic leadership at the strategic level: a new application of upper echelons theory. Leadersh. Q. 15:355-80 
Waldman DA, Ramirez GG, House RJ, Puranam P. 2001. Does leadership matter? CEO leadership attributes and profitability under conditions of perceived environmental uncertainty. Acad. Manage. J. 44:134-43

Waldman DA, Yammarino FJ. 1999. CEO charismatic leadership: levels-of-management and levels-of-analysis effects. Acad. Manage. Rev. 24:266-85

Walumbwa FO, Avolio BJ, Gardner WL, Wernsing TS, Peterson SJ. 2008. Authentic leadership: development and validation of a theory-based measure. J. Manage. 34:89-126

Walumbwa FO, Avolio BJ, Zhu W. 2008. How transformational leadership weaves its influence on individual job performance: the role of identification and efficacy beliefs. Pers. Psychol. In press

Walumbwa FO, Lawler JJ. 2003. Building effective organizations: transformational leadership, collectivist orientation, workrelated attitudes and withdrawal behaviours in three emerging economies. Int. J. Hum. Resour. Manage. 14:1083-101

Walumbwa FO, Lawler JJ, Avolio BJ. 2007. Leadership, individual differences, and work-related attitudes: a cross-culture investigation. Appl. Psychol. Int. Rev. Psychol. Appl. Rev. Int. 56:212-30

Wang H, Law KS, Hackett RD, Wang DX, Chen ZX. 2005. Leader-member exchange as a mediator of the relationship between transformational leadership and followers' performance and organizational citizenship behavior. Acad. Manage. J. 48:420-32

Washington RR, Sutton CD, Field HS. 2006. Individual differences in servant leadership: the roles of values and personality. Leadersh. Organ. Dev. J. 27:700-16

Watson WE, Kumar K, Michaelsen LK. 1993. Cultural diversity's impact on interaction process and performance-comparing homogeneous and diverse task groups. Acad. Manage. J. 36:590-602

Weber R, Camerer C, Rottenstreich Y, Knez M. 2001. The illusion of leadership: misattribution of cause in coordination games. Organ. Sci. 12:582-98

Weisband A. 2008a. Lessons about leadership at a distance and future research directions. See S Weisband 2008, pp. 149-256

Weisband A. 2008b. Research challenges for studying leadership at a distance. See $S$ Weisband 2008, pp. 3-12

Weisband S, ed. 2008. Leadership at a Distance: Research in Technologically-Supported Work. New York: Erlbaum

Whittington JL, Pitts TM, Kageler WV, Goodwin VL. 2005. Legacy leadership: the leadership wisdom of the Apostle Paul. Leadersh. Q. 16:749-70

Wofford JC, Goodwin VL, Whittington JL. 1998. A field study of a cognitive approach to understanding transformational and transactional leadership. Leadersh. Q. 9:55-84

Xiao Y, Seagull FJ, Mackenzie CF, Klein KJ, Ziegert J. 2008. Adaptation of team communication patterns. Exploring the effects of leadership at a distance: task urgency, and shared team experience. See $S$ Weisband 2008, pp. 71-96

Yammarino FJ, Dionne SD, Chun JU, Dansereau F. 2005. Leadership and levels of analysis: a state-of-the-science review. Leadersh. Q. 16:879-919

Yukl G. 1999. An evaluation of conceptual weaknesses in transformational and charismatic leadership theories. Leadersh. $Q$. 10:285-305

Yukl GA. 2006. Leadership in Organizations. Upper Saddle River, NJ: Pearson/Prentice Hall. 542 pp.

Yukl GA, Van Fleet DD. 1992. Theory and research on leadership in organizations. In Handbook of Industrial and Organizational Psychology, ed. MD Dunnette, LM. Hough, pp. 147-98. Palo Alto, CA: Consulting Psychol. Press

Zaccaro SJ, Bader P. 2003. E-leadership and the challenges of leading E-teams: minimizing the bad and maximizing the good. Organ. Dyn. 31:377-87

Zhu W, Avolio BJ, Walumbwa FO. 2008. Moderating role of follower characteristics with transformational leadership and follower work engagement. Group Organ. Manage. In press

Zigurs I. 2003. Leadership in virtual teams: oxymoron or opportunity? Organ. Dyn. 31:339-51 